\title{
A Cautious Path Forward on Accountable Care Organizations
}

Barak D. Richman, JD, PhD

Kevin A. Schulman, MD

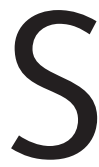

PURRING THE CREATION OF ACCOUNTABLE CARE ORganizations (ACOs) was a signature initiative in the Patient Protection and Affordable Care Act of 2010 (PPACA). To achieve potential efficiencies by having health care delivery coordinated by multiple health care entities (eg, hospitals, physician groups, clinics, health care systems), the act invites such entities to integrate in ACOs and instructs the Medicare program to share with an ACO any cost savings it can demonstrate. ${ }^{1}$ Observers are expressing concern, however, that newly established ACOs are joining health care organizations that otherwise would compete with each other, thus creating networks with dangerous market power. ${ }^{2}$ It appears that the main purpose of health care entities in forming ACOs may not be to achieve cost savings to be shared with Medicare but to strengthen negotiating power over purchasers in the private sector.

This may be the latest chapter in the steady accumulation of market power by hospitals, health care systems, and physician groups, a sequel to the waves of mergers in the 1990s when health care entities sought to counter market pressure from managed care organizations. The possibility that ACOs might further concentrate health care markets brings new urgency to understanding why these monopolies are pernicious and to considering how government can ensure that ACOs pursue efficiency rather than market power.

\section{Market Power and Health Insurance}

Although the point is not generally appreciated, monopoly power possessed by health care entities is more fiscally burdensome to consumers than monopolies in other markets. ${ }^{3}$ Ordinarily, a monopolist's pricing freedom is constrained by consumers' unwillingness to pay more than they can afford or believe the product is worth. However, health insurance in the United States hides the true price of health services from patients and thus weakens the usual constraints on monopolists' ability to raise prices. Consequently, prices most consumers would not pay (and monopolists would not charge) in the absence of insurance are paid through higher health insurance premiums for all Americans.
For legal, regulatory, and other reasons, health insurers in the United States cannot refuse to pay the high prices imposed by health care organizations, even when the price exceeds the likely value of the service to the patient. Instead, insurers are expected to cover any desired service deemed "medically necessary" by professional standards, whatever the cost. Health insurance, therefore, enables monopolists of health services to charge more than the textbook "monopoly price," earn more than the typical "monopoly profit," and capture more consumer dollars than monopolists in other industries.

Policy makers have been slow to recognize the dangers of market power in health care. In what has properly been called a failure of antitrust policy, ${ }^{4,5}$ policy makers did little to stem the accumulation of health care market power throughout the 1980s and 1990s. But the implications have been huge. For example, hospital mergers have led to estimated price increases of $40 \%$ in local markets. ${ }^{6}$ Dominant providers of insured services pose a severe challenge to health care affordability for individuals and for the nation as a whole. ${ }^{\top}$

\section{ACOs in Theory and Practice}

Still a roughly defined policy concept, ACOs are in theory an attractive solution to problems stemming from the complexity and fragmentation of the health care delivery system. ${ }^{8}$ Together with good information systems and compensation arrangements, vertical integration of complementary health care entities can achieve important efficiencies by reducing medical errors, obviating duplicative services and facilities, and coordinating elements needed to deliver highquality, patient-centered care. ${ }^{9}$

However, the PPACA invites not just vertical integration of complementary elements but also horizontal integration of competitors. Organizers of ACOs are forging collaborations among entire markets of physicians and hospitals, entities that would otherwise compete with each other. Given the extraordinary threat to economic welfare that health sector monopolies pose with health insurance in the picture, horizontal consolidation in the form of ACOs could pervert a good policy idea for bad ends.

Author Affiliations: School of Law (Dr Richman) and Health Sector Management Program, Fuqua School of Business (Drs Richman and Schulman), and Duke Clinical Research Institute and Department of Medicine, School of Medicine (Dr Schulman), Duke University, Durham, North Carolina.

Corresponding Author: Kevin A. Schulman, MD, Duke Clinical Research Institute, PO Box 17969, Durham, NC 27715 (kevin.schulman@duke.edu). 


\section{Antitrust and Regulatory Solutions}

Despite past failures, antitrust law remains a vital tool in keeping health care markets competitive. The PPACA does not protect ACOs from antitrust laws, and because health insurance confers enormous pricing freedom on dominant health care organizations, the formation of ACOs requires heightened, not relaxed, antitrust attention. In particular, antitrust enforcers and courts should be skeptical of efficiency claims and, as a matter of law, should focus their attention only on potential efficiencies and competitive effects in private markets, ignoring the arguable benefits of ACOs to Medicare.

Although conventional antitrust analysis allows efficiency claims to be weighed against harms from increased market concentration, the distorting effects of health insurance in narrowly defined monopolized markets make health care a special case. Thus, although ACOs should be allowed to integrate health care organizations vertically, significant horizontal combinations should not be countenanced unless the affected submarkets feature an ample number of effective competitors. Because of the large number of markets and the seriousness of the potential threat to economic welfare, regulators-either antitrust authorities or Medicare itself-should impose a preapproval process, with the burden of proof on ACO proponents, to prevent the formation of ACOs that dangerously concentrate health care markets.

Given its commitment to performance measurement, Medicare should additionally require ACOs to meet normative or national standards of efficiency in serving both private and Medicare patients. Because such a test would measure performance in terms of risk-adjusted per capita costs-implicitly incorporating both price and service use- an ACO would have difficulty passing the test if it were exploiting its monopoly power in the private sector. Medicare might also condition its sharing of savings with an ACO on the latter's demonstration that its prices to private payers have not increased because of its acquisition of market power; an ACO found to be abusing its power could be threatened with dissolution.

States also can play an important role in counteracting the market power of health care organizations. Some states might choose to institute rate caps, a policy that met success in a few states in the 1970 s and early $1980 \mathrm{~s},{ }^{10}$ or to adopt an all-payer rate-setting program. Although price regulation might be palatable only if other efforts fail to curb the market power of health care organizations, policy makers should remember that the health care monopoly problem exists today largely because horizontal mergers were permitted to create large health care systems that failed to produce their promised efficiencies. Current health care prices reflect the costs of these monopolies without many benefits from integration.

\section{Conclusion}

Innovative delivery systems must be part of the solution to cost and quality problems. Real benefits can flow from connectivity among health care organizations as well as between health care entities and patients, reducing low-value services, managing chronic diseases, and enhancing prevention. However, organizations that achieve these goals can take many forms. There are compelling reasons to experiment with organizational forms, as envisioned in the PPACA, and to encourage competition among the most promising ones. For example, rather than emphasize hospitalcentered ACOs that rely on "bricks-and-mortar" vertical integration, which is arguably obsolete due to advances in information technology, a clearer path in this era of ambulatory care would be to build ACOs around multispecialty physician practices or independent physician associations that do not include most of the physicians in a geographic market. Such arrangements could lower overhead costs while improving quality without exacerbating the health care monopoly problem.

Whatever the approach, the overriding policy goal must be to achieve improvements in care while challenging, rather than playing into the hands of, health care organizations that seek to exploit market dominance. Properly regulated ACOs can be effective instruments for solving the underappreciated problem of monopoly in health care markets and health care delivery.

Conflict of Interest Disclosures: All authors have completed and submitted the ICMJE Form for Disclosure of Potential Conflicts of Interest. Dr Richman reported receiving consulting income from Blue Cross Blue Shield of Rhode Island. Dr Schulman reported receiving consulting income from Blue Cross Blue Shield of North Carolina. Dr Schulman has made available online a detailed listing of disclosures (http://www.dcri.duke.edu/about-us/conflict-of-interest/).

Additional Contributions: Clark C. Havighurst, JD, Duke University, and Robert A. Berenson, MD, Urban Institute, contributed to writing the manuscript. Neither received financial compensation. Damon $M$. Seils, MA, Duke University, provided editorial assistance and assisted with manuscript preparation. Mr Seils did not receive compensation for his assistance apart from his employment at the institution where the work was conducted.

\section{REFERENCES}

1. Patient Protection and Affordable Care Act $\S 3022$ and $\S 10307$, Pub L No. 111148,124 Stat 119.

2. Greaney TL. Accountable care organizations-the fork in the road. N Eng/ J Med. 2011;364(1):e1.

3. Havighurst CC, Richman BD. Distributive injustice(s) in American health care Law Contemp Probl. 2006;69(7):14-20.

4. Richman BD. Antitrust and nonprofit hospital mergers: a return to basics. Univ PA Law Rev. 2007;156(1):121-150.

5. Greaney TL. Night landings on an aircraft carrier: hospital mergers and antitrust law. Am J Law Med. 1997;23(2-3):191-220.

6. Dafny L. Estimation and identification of merger effects: an application of hospital mergers. J Law Econ. 2009;52(3):523-550.

7. Berenson RA, Ginsburg PB, Kemper N. Unchecked provider clout in California foreshadows challenges to health reform. Health Aff (Millwood). 2010;29 (4):699-705

8. Elhauge E, ed. The Fragmentation of US Health Care. New York, NY: Oxford University Press; 2010.

9. Enthoven AC, Tollen LA. Competition in health care: it takes systems to pursue quality and efficiency. Health Aff (Millwood). 2005(suppl Web exclusives): W5-420-W5-433.

10. Atkinson G. State Hospital Rate-Setting Revisited. New York, NY: Commonwealth Fund; 2009. Issue Brief 69 